\title{
Appraisal of Process Mapping in Heavy Engineering Projects: a Case of Nigeria East-West Coastal Highway
}

\author{
Samuel Ekung ${ }^{1}$, Lashinde Adeniran ${ }^{2}$, Emmanuel Adu ${ }^{2}$ \\ ${ }^{1}$ School of Built Environment, University of Salford, M5 4WT, United Kingdom \\ ${ }^{2}$ Department of Quantity Surveying, Faculty of Environmental Studies, University of Uyo, Nigeria
}

\begin{abstract}
The need to improve project delivery process is one of the leading advocacies of relevant construction industry reports. Improved process is sine qua non for improve performance. Critical to the improvement process, is the need to assess construction process' capability to meet design and production requirements. The present study examined process mapping of a cable-stayed bridge in the Nigeria's east-west coastal highway project. Qualitative data was collected through a three phase process mapping protocol using mainly self-generate, one-on-one interview and focus group. Twenty non-related sub-processes were identified from four pre-construction stages: investigation; feasibility; design; and tender. Integrative definition (IDEFO) and Unified Language Modelling (UML) are used to map the feasibility, design and the design sub-processes. The mapping indicates the design sequence is iterative and factually flexible until such a point where functional design satisfies appropriate forcing test. The study provides medium for communicating complex construction functions thereby facilitating common understanding in the way projects are delivered with appropriate information about inputs, output and resources.
\end{abstract}

Keywords: idefo; cable-stay Bridge; costal engineering; process mapping; UML

\section{INTRODUCTION}

In an attempt to address the imminent problems facing the construction industry and the delivery of large construction projects in particular, the attention of researchers in construction management has shifted towards front-end issues for decades now (Tang, 2009). Inherent problems include: fragmented processes (Cartlidge, 2011); resistant to change (McCabe, 2007); nature of the construction process (Arif, 2013); and lack of process models and industry standards (Yeomans et al., 2006). However, Blasma et al (2005) considers these problems inconsequential because they constitute basic characteristics of the industry itself. Supporting this view, Arif (2013) opined they are mere perception bias to the enthronement of process improvement.

While significant success has been achieved through research into other front-end issues such as risk management, project governance, and quality improvement (Grimm et al.; 2012; Adedokun et al., 2012; Flyvberg 2009; Gil \& Laundryman 2012; Pighini et al., 2011; 
and Patel \& Robinson, 2010); limited literature exist in construction management on process mapping and process improvement in heavy engineering projects.

Process mapping deals with the identification, documentation, analysis and developing a process for improvement (Anjard, 1998). Coastal engineering constructions are a broad range of forms which are influenced by the action of water, tide and currents, wave actions and highest level risks (Simm \& Cruickshank, 1998). Process improvements have been studied but research effort focused mainly on the delivery methods rather than the process of delivery (Larsson \& Simonsson, 2012; Ostenfiel \& Anderson, 2011; and Nadim \& Goulding, 2011).

Extant literature reveals limited studies exist in process improvement generally and preconstruction process mapping in particular. Existing studies on process mapping focus on conceptual issues and benefits (Anjard, 1998; Austin \& Steele, 2001; Kagioglou, 2002 \& Klotz et al., 2008). These studies have stopped short of considering processes in the delivery of heavy engineering projects; neither is the processes involve in a typical costal engineering such as cable-stay bridge apparent. While the cables stay bridge systems have been studied in the context of engineering practice and standards (Grabow, 2004 and Azarnejad, 2011); there is therefore no empirical research on process mapping in cable stay systems.

The statuesque remain despite the vast construction challenges surrounding the delivery of cable-stayed bridges. The present study therefore examined processes involved in the delivery of cable-stayed bridge system in order to generate a process map that will facilitate process re-engineering. The objective is to produce process maps of each stage in the preconstruction stages as a critical step in process improvement.

The need is derived from the current global initiative of seeking co-operation and continuous improvement in the performance of construction industries. Knowledge of heavy capital projects have elude most cost and construction managers in developing countries and this practice has been designated an exclusive practice of certain firms with vast expertise content in developed countries.

The emphasis however, is on value creation, waste elimination, improved efficiency and elimination of non-value adding chains. Fox et al. (2002) identified the need to assess the capability of a construction process to determine whether it is capable of meeting design requirements. The need for such capability assessment is to ensure that incapable processes are improved until they are certified capable. The study seeks to address problems relating to design risks identified by an earlier study (Ekung, 2013) on the Nigeria's east-west coastal highway project.

\section{Construction Process}

A process is defined as a group of activities or tasks to be carried out in order to generate a product. A construction process has a goal, input, output, utilizes resources with a number of activities in some order and creates value in realisation (McCabe, 2007).

An activity on the other hand, is the least unit of work with definite duration; logical relationships with other activities in the project which consumes valuable resources and have associated cost (Egbu et al, 2004). Critical to the interest of this paper in the definitions is the existence of logical relationship that is, a flow in event. Such flow of relationship is essential in the mapping of construction processes. 


\section{Construction Process Mapping and Process Maps}

The need to manage or mapped a process is critical since the performance of a construction project equals the performance of the process (Anjard, 1998). Process mapping is an intermediary step to process improvement (Klotz, 2008). Process mapping is aimed at providing a means of communicating complex construction functions; and formalising process thereby facilitating common understanding of the way in which process are delivered with information. It minimises production cycle duration and increase productivity (Baressi, 2013). Process mapping enhances work visibility and improved visibility enhances communication. It is used as a frame of reference which shows the process of accomplishing work in a construction project. It is known to provide a snapshot of inputs, functions, steps, output in an entire construction processes.

Process map on the other hand, provides alternatives through the project delivery process; pinpoint improvement opportunities, and evaluates, accomplish and reinforces performances. Modelling can be done in two different levels: modelling individual processes as the need arises; and modelling all processes fully at a time (Fowler, 2009).

\section{Techniques in Process Mapping}

A plethora of techniques abound in business and manufacturing sector that can be used to map construction processes for improvement. Available for use includes remote flow chart diagram to integrative definition (IDEFO) and unified modelling language (UML). The study utilises IDEFO and UML in the mapping exercise. Different procedures are used in process mapping but the top-down process flow "peeling the onion" is widely opinionated in the literature (Anjard, 1998). In the peel down approach, mapping iteratively began at the highest (macro-level) with many decision points. Process analyst canvasses 5 to 20 processes (Ob cit) which can be peeled down into other levels. At the sub-process level 5 to 15 activities is appropriate (Anjard, 1998). However, the level of detail is tied to the purpose of the map.

\section{Unified Modelling Language}

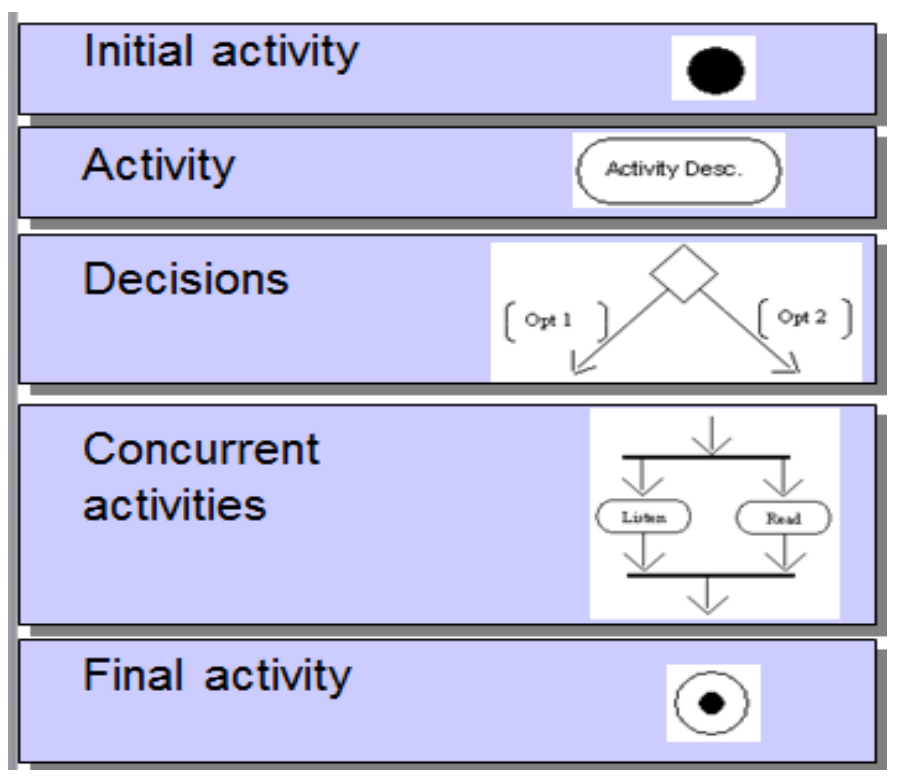

Figure 1. Notations in Unified Modelling Language (Barresi, 2013). 
This is an open modelling standard maintained by the Object Management Group (OMG). OMG (1997) described UML as 'a graphical language for visualising, specifying, constructing, and documenting the artefacts of a software-intensive system'. UML states the goals, the processes and the resources involved in a piece of work. It specifies; visualise, document problems, captures and leverage problem solving (Barressi, 2013). Series of diagram can be produce using the UML: use case; activity; sequence; object, state; component diagrams etc. Key notations in the UML are presented in Figure 1.

\title{
Integrative Definition (IDEFO)
}

IDEFO is used mainly to generate 'functional maps' in process mapping. A function map is a planned illustration of roles, tasks, or group of task within the model system (Baressi, 2013). Two major components are modelled: roles or data and objects. They are inter-related using connecting arrows. Boxes are used to picture where action takes place in a designated role; each box has a name and a number inside towards the lower right corner.

\section{The Nigeria East-West Coastal Highway}

The Nigeria East-West Coastal highway is unique and the very first in the region. The coastal road span $731 \mathrm{Km}$ with over $206 \mathrm{Km}$ straddling over barrier Island forest, fresh water swamps, mangrove swamps and inland water way. Engineering design of the project shows an alignment that crosses almost 60 water bodies requiring 180 bridges. The world fifth longest cable stayed bridge is to be constructed in this project. The unique features have placed significant impetus on the need to study the risk attributes of the project in order to improve the delivery process. Road transportation accounts for over $90 \%$ of the movement of people in Nigeria (Ighodaro, 2009) including goods and services. The traveling distance between two ends Calabar and Lagos in the project takes 10 to 12 hours via road; and on completion, this travelling time will be half. According to Mboji (2012):

\begin{abstract}
"The planned road therefore aimed to open, the locked up 1,000 communities to assess the economic opportunities and attract investment in abundant natural resources. It will promote direct access to water ways that are underutilised at the moment and to encouraged the establishment and growth of maritime industries; promote the exploitation of natural resources of the Niger Delta such as oil and gas, sand for glass making, ocean terminals, ship repairs and maintenance, provide market for major economic activities such as fishing, to unlock the region vast tourism potentials in ocean viewing, natural beaches, eco-sanctuaries, spawning grounds, spectacles of the world's fifth longest cable-stayed bridge and eight longest suspension bridge and expansion of service sector of the contiguous states".
\end{abstract}

It will facilitate regional integration and linkage of coastal economies to the national economy in Nigeria.

\section{RESEARCH METHODOLOGY}

Process mapping began with information gathering about the process to be mapped. This can be in three ways (Barresi, 2013): self-generate, one-on-one interviews and group interviews. Self-generate involved simply itemising the processes involved in achieving a 
task. The second involve chain of interviews one-on-one with relevant stakeholders. The third approach involves bringing a group of stakeholders together for interview (Fowler, 2009). In order to achieve its objectives, the study adopts three tier processes. First, extensive literature search was carried out in order to generate the processes adopted by best in class engineering practices across the globe (self-generate). Second, 12 engineers from leading consulting engineering practices in Akwa Ibom State, Nigeria were interviewed (one-on-one interview). The respondents were selected based on the criteria of having participated in the construction or design of a bridge project in the past. This state was selected because first, it is a constituent state in the project; second, the proposed cable-stayed bridge situates within its territory, third, one of the leading consultant organisation involve in the design of this project is in this region. The respondents were asked questions relating to the engineering procedure they will adopt in designing a functional and implementable cable-stayed bridge such as the one envisaged in the Nigeria's east-west coastal highway project. The inputs from steps one and two above were aggregated to map the pre-construction processes using UML and IDEFO. Third, Process maps generated were afterwards validated by a focus group selected using convenience sampling (group interviews). The participants were drawn mainly from the population of engineers interviewed. Eight (8) engineers participated in the focus group discussion. The focus group generated views which were subsequently incorporated in the final map presented in this study. Clarke (2013) considers the use of focus group suitable for validating result of a study. A focus group membership of $5-15$ participants is within threshold considered adequate in research (Ob cit).

\section{RESULTS AND DISCUSSION}

All coastal constructions are developed in six major processes (COWI, 2012): investigation; feasibility; design; tender; construction; and operation and maintenance (Figure $3)$. Twenty sub-processes are mapped in the pre-construction stages of the cable stayed bridge. Figure 2 is the high level diagram of the concept (IDEFO level 0). Investigation phase sub-processes include condition survey, Bathymetry, under water dive inspection and geotechnical analysis. Feasibility phase involves six sub-processes: need study; design data analysis; concept design; costing; procurement and environmental impact assessment (Figure 4). Need study identifies the problem to be solved (the bridge); design data examines engineering requirements, concept design formulates an outline of the proposed scheme, costing estimate budget while procurement analysis identify criteria for measuring success and defines strategy for delivery. The design process has six steps (Figure 5): establish design basis; design data studies; durability design; structural design, M \& E installations design; and operational risk assessment.

In Figure 5, alternative design options to the identified problem are articulated in systematic sequence at the reconnaissance and feasibility studies to ensure relevant alternatives are pinpointed earlier and refined in successive restatement. According to PDH Engineer (2008), the process is not limited to this stage, as the process is progressing; evolving alternative may be introduced as the need presents itself. This pre-supposes that the design process is factually flexible in principle. However, there is need therefore for the design flexibility to be extended to the construction phase of the facility. This is to address the high risk of construction intolerance associated with costal engineering projects. In so doing, emphasis should be placed on what can be achieved at that level not necessarily what standards dictates. 


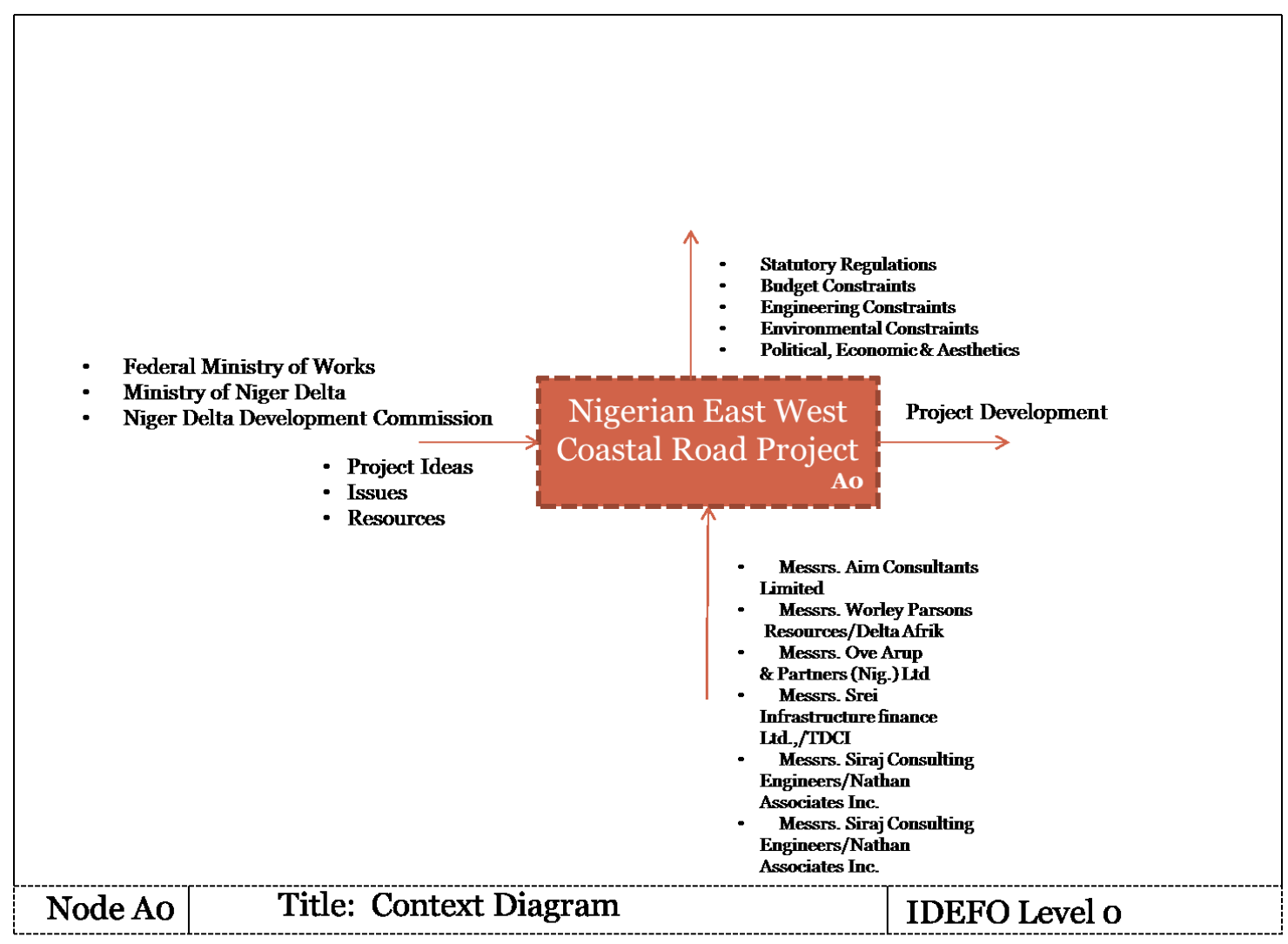

Figure 2. Project Concept IDEFO Level 0.

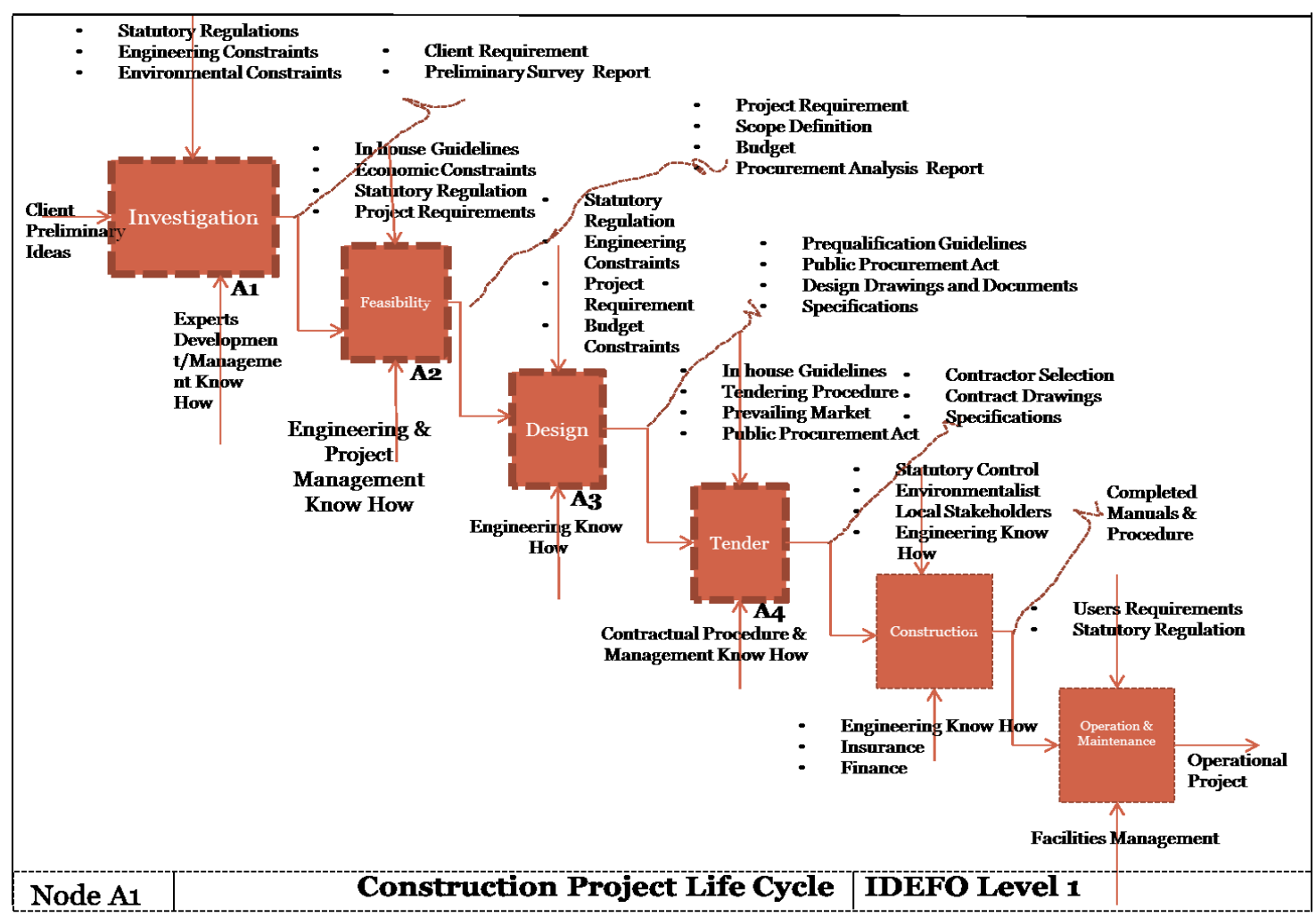

Figure 3. IDEFO Level 1-Main Processes in Coastal Construction. 


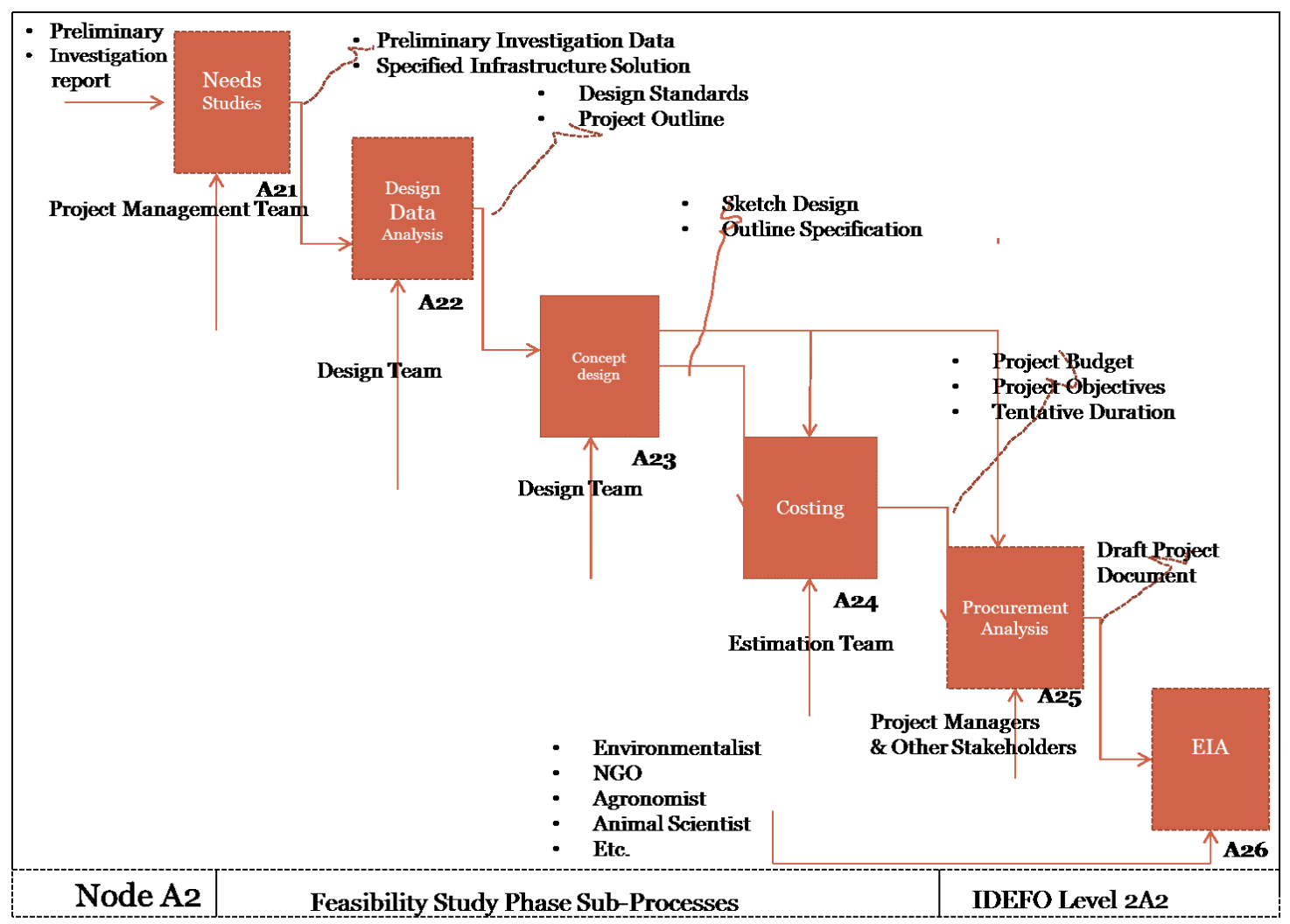

Figure 4. Sub Processes in Feasibility (IDEFO Level 2B).

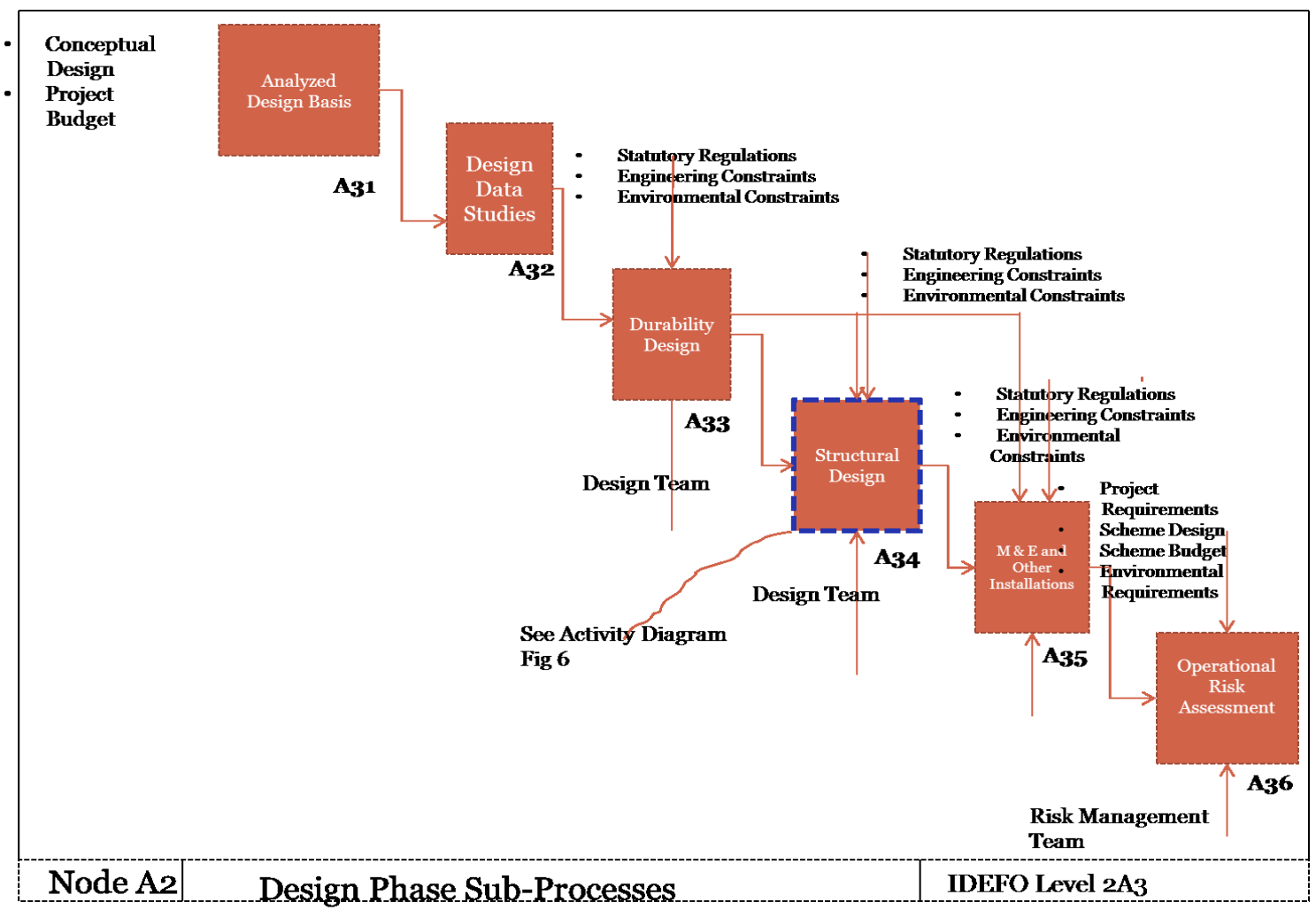

Figure 5. Sub Processes in Design (IDEFO Level 2C). 


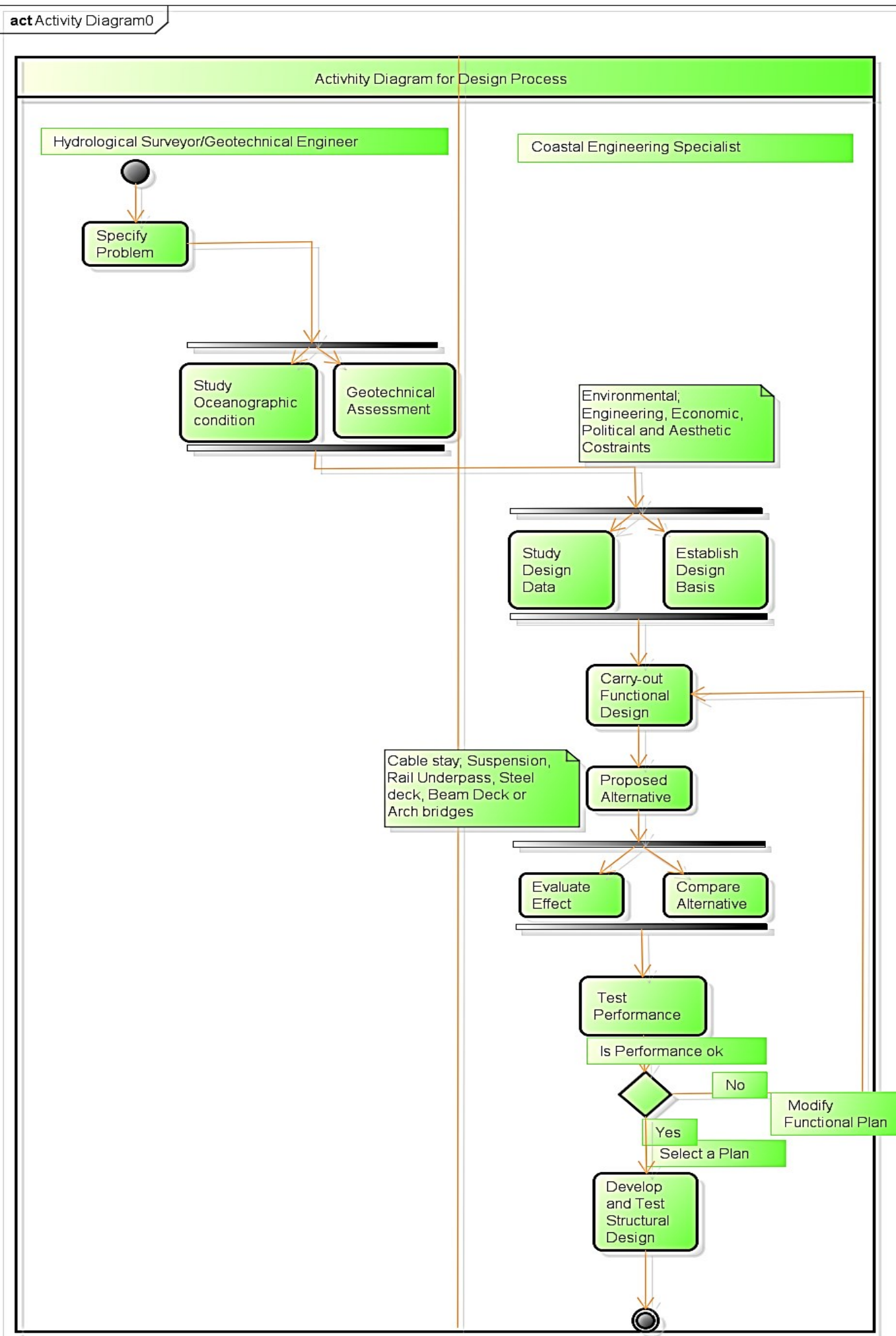

Figure 6. UML Activity Diagram for Structural Design Sub-Process. 
The next step evaluates and compares the effect of different designs with and without plans. The plan refers to the different proposed solution put forward to solve a particular problem. Four effects are measured: the environmental quality; cultural and aesthetics resources; the regional economic development; and the OSE (other social effects) - not captured in other effect's category.

In plan comparison, emphasis is placed on the dissimilarity among alternative plans in preceding steps. Monetary and non-monetary effect is equally compared and if functional requirement are not met, the cycle return to functional design level. After due evaluation of feasible alternatives plans, their effects and public comments, the plan with most national economic development is selected and recommended for implementation.

\section{CONCLUSIONS}

In order to enhance construction re-engineering process, the study carried-out process mapping of four pre-construction stages in cable-stayed bridge system. With inputs from engineers in Nigeria and other global best in class standards generated collectively and individually were used to produce the process maps. The need for the mapping in the context of Nigeria's east-west coastal highway project was derived from an earlier study by the authors. The referenced study identified incompetent design and inexperience design team as some of the critical risk factors in the project.

The maps outline six basic processes in the project life cycle production while twenty sub-processes were identified in the four pre-construction stages. The design process is seen to be iterative; evolving and introducing alternatives as the need presents itself. This flexibility is as a result of the nature of coastal engineering environment. It is therefore imperative for the flexibility to be extended to the construction stage in order to address tolerance risk which is significantly very high in costal engineering projects. The study has communicated complex construction functions in maps with information on the inputs, the resources and the expected outputs. It is a justifiable mitigation step in solving design related risks in the east-west coastal engineering projects.

\section{References}

[1] Adedokun O.A., Ogunsemi D.R., Aje I.O., Dairo D.O. (2012). Evaluation of Risk Analysis Techniques in Selected Large Construction Companies in Nigeria, Emerald Group Publishing, Pre-printed version.

[2] Arif M. (2013). Quality and Process Improvement in Construction, Lecture Materials, Project \& Process Systems, School of Built Environment, University of Salford.

[3] Anjard R., Facilities 16(3) (1998) 79-81.

[4] Austin S., Steele M., Design Studies 22(3) (2001) 211-232.

[5] Azarnejad A., McWhinnie K., Tadros G., Stasky J. (2011). Cable-stayed as an Alternative for Medium and Short and Short Span Bridges, Proceeding of Annual Conference of the Transportation of Canada, Alberta. 
[6] Barresi S. (2013). Process Modelling Introduction to UML and IDEFO, PG Level 7 Project and Project Systems Learning Packages, School of Built Environment, University of Salford, 2012/2013 session.

[7] Blismas N., Pendlebury M. Alister G., Pasquire C. (2005). Constraints to the Use of off- Site production on Construction Projects, University of Loughborough, a Creative Commons Report.

[8] Cartlidge D. (2011). New Aspect of Quantity Surveying Practice, $3^{\text {rd }}$ Edition, London: Routledge Spon Press.

[9] Clarke A. (2013). What are Focus Groups? SPORTS-Post Graduate Research Lectures Materials, University of Salford, 2012/2013 Session.

[10] Clausner J. E., Melby J.A., Scheffner N.W., Butler H.L. (2008). Coastal Engineering - Planning and design Process, Huston: PDHEngineer.com Continuing Education for Engineers.

[11] COWI (2012). Marine and Coastal Engineering, Ocean \& Coastal Consultants, Inc., North America, available online accessed 2/3/2013: http://www.cowi.com/menu/project/Bridge

[12] Egbu C., Ellis R., Gorse C. (2004). The Practice of Construction Management, Barry Fryer, $4^{\text {th }}$ Edition, Oxford: Blackwell Science Publishing Co.

[13] Ekung S.B. (2013). Pre-construction Process mapping, Risk Register and Matrices and Process Improvement in the Nigeria's East-West coastal Road as an Iconic Project, Project \& Project System Coursework, School of Built Environment, University of Salford, Manchester, 2012/13 session.

[14] Flyvberg B., Oxford Review of Economic Policy 25(3) (2009) 344-367.

[15] Fowler M. (2009). UML Distilled $3^{\text {rd }}$ edition $-A$ Brief Guide to the Standard Object Modelling Language, Addison-Wesley.

[16] Fox S., Matsh L., Cockerham G., Construction Management and Economic 21 (2002) 7-10.

[17] Gil N., Laundryman C. (2012). The Leadership and Governance of Megaprojects, CID Technical Report No 3/2012, Centre for Infrastructure Development, Manchester Business School, University of Manchester.

[18] Grimm C., Woffler T., Bacmann D., Schuttrumpf H. (2012). Risk Management in Coastal Engineering, Applied Coastal Research Projects for Northern Germany, Water and Waste, 53-55.

[19] J. Heumann (2003) Introduction to Business Modelling using UML available at accessed 23/01/13: http://www.ibm.com/developerworks/rational/library/360.html

[20] Kagioglou M. (2002). Mapping the Production Process: a Case Study, Proceeding of International Group for Lean Construction, Gramado, Brazil.

[21] Klotz L., Horman M., Bi H., Bechtel J., International Journal of Productivity and Performance Management 57(8) (2008) 623-636. 
[22] Larsson J., Simonsson P. (2012). Barriers and Drivers for Increased Use of Offsite Bridge Construction in Sweden, in: Smith, S.D (Ed) Proceeding 28th Annual ARCOM Conference, 3-5 September 2012, Edinburgh, UK, Association of Researchers in Construction Management, 751-761.

[23] Mccabe S. (2007). Benchmarking in Construction, Chichester: John Willey \& Sons, $1-24$.

[24] Nadim W., Goulding J. S., Engineering, Construction and Architectural Management 18(1) (2011) 81-101.

[25] Ostenfield K.H., Anderson E.Y. (2011). Major Bridge Projects - a Multidisciplinary Approach available online: retrieve 22/2/13 http://bscw-app1.ethz.ch/pub/bscw.cgi/d376865/07

[26] Patel M., Robinson H., Journal of Financial Management of Property and Construction 15(3) (2010) 216-234.

[27] Pighini M., Wallace P., Schwartz A., Flieger R. (2011). Improving Governance of Public Sector Construction Projects, Deloitte Financial Advisory Services.

[28] Simm J., Cruickshank I. (1998). Construction Risk in Coastal Engineering, London: Thomas Telford, 155-178.

[29] Tang S.M.T. (2009). How Front End Factors Affect project Outcomes: A Look at Four Infrastructure Projects in Asia, Working Paper No 34, Collaboratory for Research on Global Projects.

[30] Yeomans S.G., Bouchlaghem N.M., El-Hamalawi A., Automation in Construction 15(2) (2006) 139-149. 